\title{
Applied Exponential Smoothing Holt-Winter Method for Rainfall Forecast in Mataram City
}

Dewi Darma Pertiwi

Department of Statistics, Universitas Muhammadiyah Semarang, Semarang 50254, Indonesia

dewidarmapertiwi@gmail.com (coresponden author)

Article history :

Received : 22 Sep 2020

Accepted : 25 Sep 2020

Available online : 30 Sep 2020

\section{ABSTRACT}

Weather conditions in the city of Mataram tend to be erratic and difficult to forcast, such as the condition of rainfall data in 2018 which changes over a certain period of time so that the weather is difficult to forcast accurately. In this study, we propose the Exponential Smoothing Holt-Winter method to forecast rainfall in the city of Mataram, so that it can be a decision support for various interested sectors. This method has been tested using secondary data from the Mataram City Central Bureau of Statistics for the period January 2014 to 2018 and evaluated using Mean Absolute Deviation (MAD), Mean Squared Error (MSE) and Mean Absolute Percentage Error (MAPE). The results of this study indicate that using the Exponential Smoothing Holt-Winter method yields better results, each of which is MAPE 142.3, MAD 95.6 and MSD value 24988.7 and the data smoothing value is obtained for the smallest combination value of $\alpha 0.2, \beta 0.1$, and $\gamma 0.1$. It can be concluded that the proposed method can provide better information and can be used to forcast rainfall in Mataram City for the next 12 periods.

Keywords : Exponential smoothing holt-winter, mataram, curah hujan.

This is an open access article under the CC-BY-SA license.

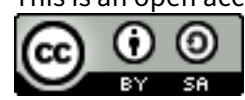




\section{INTRODUCTION}

The extreme weather conditions that occur in the city of Mataram can be seen in the rainfall data for 2014 to 2018 and experience fluctuating conditions over a certain period of time making it difficult to forcast the weather accurately (Pascawati et al. 2019). Therefore, accurate weather information based on scientific studies is very important as a reference (Noviandi and Ilham 2020). This information can be in the form of forecasts of rainfall both in the short term and in the long term. Forecasting the amount of rainfall is very important (Wichitarapongsakun et al. 2016; Dhamodharavadhani and Rathipriya 2019; Noviandi and Ilham 2020) information because it can be used to plan several production sectors such as agricultural production (Hartomo, Subanar, and Winarko 2015), plantations (Zhu et al. 2020), fisheries (Dunstan et al. 2018), aviation (Chen and Wang 2019), public service (Golding et al. 2019), and so on. In addition, this information is useful for early detection of disasters that may occur due to extreme rainfall (Zhu et al. 2020).

In recent years, the City of Mataram has experienced weather conditions that tend to be erratic and unpredictable. Therefore, it is necessary to have clear information about the amount of rainfall or the period of rainfall. The weather forecast data report in the City of Mataram is very important. Thus, this study aims to forcast the amount of rainfall and the rainfall period using the Holt-Winter method. The use of the HoltWinter method in this study, because the data used is time series data with a single variable. So this study only analyzes the amount of rainfall based on historical monthly rainfall data that occurs in the city of Mataram.

\section{BASIC THEORY AND METHODS}

\subsection{Forcasting}

The forecast is to forcast or forecast a future situation using certain methods. The forecast is made by using the best information to achieve the desired targets. Forcasting events that may occur in the future is needed in order to be ready (Zhu et al. 2020).

\subsection{Decomposition and Seational Adjustments}

For forecasting purposes, time series data are often decomposed into four main components, namely:

- Trend, which is characterized by a decrease or increase in data in changes in time.

- Seasonal (seasional), in the data plot according to time, there are repeated (and regular) fluctuations in a certain period of time.

- Cyclic (cyclical) or cyclical patterns, generally the time period is relatively longer than seasonal.

- Irregular components in the form of random patterns

\subsection{Trend Component Modeling}

The trend form of time series data can be modeled in various ways, such as using a deterministic model, namely:

- $\quad$ by using a linear filtering model

- trend regression over time

\subsection{Exponential Smoothing}

Exponential smoothing is a general rule for the use of an exponential window function to smooth time series data. Whereas past observations are equally weighted in the simple, moving average, exponential functions are used to exponentially assign decreasing amounts over time. It is easy to learn and easily applied to determine based on prior assumptions of the user, such as seasonality. For the analysis of time series data, exponential smoothing is often used.

Exponential smoothing is one of many window features used to process smooth data and act as low-pass filters to remove high frequency noise. This method is preceded by the recurrent exponential window functions used by Poisson in turns dating to the 19th century and the use of recurring motion averages from their turbulence studies in the 1940s by Kolmogorov and Zurbenko.

The raw data sequence is often $x_{t}$ from $t=0$, and the exponential smoothing algorithm output is commonly $s_{t}$ and can be considered a best estimate of the next value of $x$. The simplest form of exponential smoothing is given by the Eq. 1 when the sequence of observations commences at time $t=0$, equations should be numbered serially throughout the paper.

$$
\begin{aligned}
& s_{0}=x_{0} \\
& s_{t}=\alpha x_{t}+(1-\alpha) s_{t-1}, t>0
\end{aligned}
$$

where, $\alpha$ is the smoothing factor, and $0<\alpha<1$.

For detailed explanation you can read the report by (Hyndman et al. 2010).

\subsection{Holt-Winter Exponential Smoothing Method}

The Holt-Winters exponential smoothing method is based on three elements, namely stationary, trend and seasonal elements for each period and provides three weights in the forcast, namely $\alpha, \beta$, and $\gamma$. There are two Holt-Winters models that can be used, including the Holt-Winters Additive model and the Holt-Winters Multiplicative model:

\subsubsection{Holt-Winter Aditif Model}

There are several common formulas of the HoltWinter Additive method The Holt-Winters are as follows:

- Eq. 2 to calculate trend smoothing; $s_{t}=\alpha\left(X_{t}-l_{t-L}\right)+(1-\alpha)\left(s_{t-1}+b_{t-1}\right)$

- Eq. 3 for calculating seasonal smoothing on 
additive models;

$$
s_{t}=\beta\left(S_{t}-S_{t-1}\right)+(1-\beta) b_{t-1}
$$

- Eq. 4 for calculating seasonal smoothing on additive models;

$$
s_{t}=\gamma\left(X_{t}-S_{t-1}\right)+(1-\gamma) I_{t-L}
$$

- To calculate the forcast value of Holt-Winters exponential smoothing on the additive model the following Eq. 5.

$$
b_{t}=\beta\left(S_{t}-S_{t-1}\right)+(1-\beta) b_{t-1}
$$

For detaild formulas to calculate you can read by (Metcalfe and Cowpertwait 2009).

\subsubsection{Holt-Winters Multiplicative model:}

There are several common formulas of the HoltWinter Additive method:

- Eq. 6 to calculate the exponential smoothing of the Holt Winters;

$$
S_{t}=\alpha \frac{X_{t}}{I_{t-L}}(1-\alpha)\left(S_{t-1}+b_{t-1}\right)
$$

- Eq. 7 to calculate trend smoothing;

$$
b_{t}=\beta\left(S_{t}-S_{t-1}\right)+(1-\beta) b_{t-1}
$$

- Eq. 8 for calculating seasonal smoothing on a multiplier model;

$$
S_{t}=\gamma \frac{X_{t}}{S_{t}}(1-\gamma)+I_{t-L}
$$

- To calculate the forcast value of Holt-Winters exponential smoothing in a multiplier model, Eq. 9 is used.

$$
F_{t+m}=\left(S_{t}-m b_{t}\right)+I_{t-L+M}
$$

For detaild formulas to calculate you can read by (Metcalfe and Cowpertwait 2009).

\subsection{Goodness Model Criteria}

There are several common Several measures of model goodness that are often used are the mean absolute deviation (MAD) in Eq. 10, mean squared error (MSE) in Eq. 11, and mean absolute percent (MAPE) approximations in Eq. (12).

$$
\begin{gathered}
M A D=\left(\frac{1}{n} \sum_{t-1}^{n}\left|Y_{t}-\hat{Y}_{t}\right|\right) \\
M S D=\frac{1}{n} \sum_{t-1}^{n}\left|Y_{t}-\hat{Y}_{t}\right|^{2} \\
M A P E=\frac{1}{n} \sum_{t-1}^{n}\left|\frac{Y_{t}-\hat{Y}_{t}}{Y_{t}}\right| \times 100 \%
\end{gathered}
$$

\section{RESULTS AND DISCUSSIONS}

The Mataram City rainfall data used in this study were sourced from the monthly rainfall data in the City of Mataram for the period January 2014 to December 2018. Figure 1 shows the results of the time series data plot for the rainfall in Mataram City.

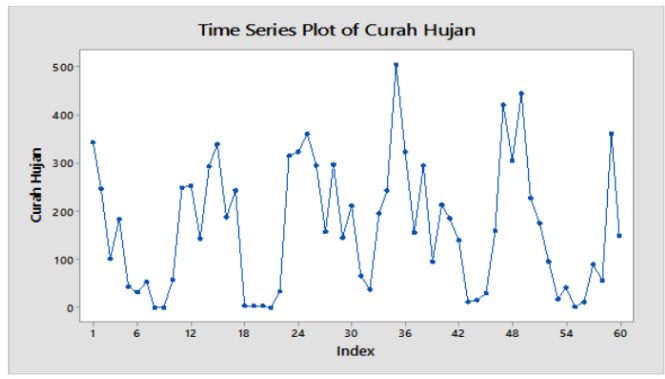

Fig. 1. Result actual rainfall data for the City of Mataram for the period January 2014 to December 2018.

Table 1 shows the estimation of smoothing constants, it can be seen that the proposed method produces the smallest MAPE, MAD, and MSD values, namely in the combination $\alpha=0.2 \beta=0.1 \gamma=0.1$, the MAPE value is 142.3 and the MAD value is 95.6 and MSD value of 24988.7 .

Table 1.The caption must be shown before the table.

\begin{tabular}{|c|c|c|c|c|}
\hline No & $\begin{array}{c}\text { Smoothing } \\
\text { constants }\end{array}$ & MAPE & MAD & MSD \\
\hline 1 & $\begin{array}{c}\alpha=0.1 \beta=0.1 \\
\gamma=0.1\end{array}$ & 156.1 & 101.9 & 20380.9 \\
\hline 2 & $\begin{array}{c}\alpha=0.1 \beta=0.1 \\
\gamma=0.2\end{array}$ & 164.7 & 117.9 & 31944.0 \\
\hline 3 & $\begin{array}{c}\alpha=0.2 \beta=0.3 \\
\gamma=0.2\end{array}$ & 165.2 & 115.7 & 42145.4 \\
\hline 4 & $\begin{array}{c}\alpha=0.2 \beta=0.1 \\
\gamma=0.1\end{array}$ & 142.3 & 95.6 & 24988.7 \\
\hline 5 & $\begin{array}{c}\alpha=0.2 \beta=0.2 \\
\gamma=0.2\end{array}$ & 153.9 & 122.3 & 56372.2 \\
\hline 6 & $\begin{array}{c}\alpha=0.3 \beta=0.2 \\
\gamma=0.1\end{array}$ & 154.1 & 101.7 & 32966.6 \\
\hline 7 & $\begin{array}{c}\alpha=0.3 \beta=0.1 \\
\gamma=0.2\end{array}$ & 150.3 & 108.7 & 40685.1 \\
\hline 8 & $\begin{array}{c}\alpha=0.4 \beta=0.1 \\
\gamma=0.1\end{array}$ & 145.1 & 89.8 & 22855.0 \\
\hline 9 & $\begin{array}{c}\alpha=0.3 \beta=0.3 \\
\gamma=0.1\end{array}$ & 164.3 & 108.7 & 406851 \\
\hline
\end{tabular}

Figure 2 shows the results of forecasting rainfall in Mataram city, using the Exponential Smooting HoltWinter multiplicative method for the next 12 periods.

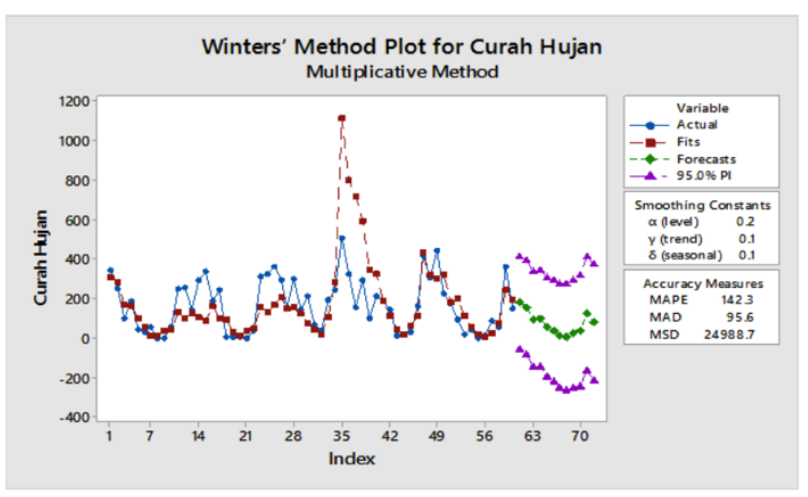

Fig. 2. The results of forecasting rainfall in Mataram city for the next 12 periods.

\section{CONCLUSION}

Rainfall forecasting in the city of Mataram for the next 12 periods or the next year using the Holt-Winters 
Exponential Smoothing method has increased and decreased. The results obtained from the smoothing of the rainfall data in the city of Mataram for the smallest combination value $\alpha$ of $0.2 \beta$ of 0.1 and $\gamma$ of 0.1 and the MAPE value of 142.3 and the MAD value of 95.6 and the MSD value of 24988.7 .

\section{REFERENCES}

Chen, Zhenhua, and Yuxuan Wang. 2019. "Impacts of Severe Weather Events on High-Speed Rail and Aviation Delays." Transportation Research Part D: Transport and Environment 69 (April): 168-83. https://doi.org/10.1016/j.trd.2019.01.030.

Dhamodharavadhani, S., and R. Rathipriya. 2019. "Region-Wise Rainfall Prediction Using MapReduce-Based Exponential Smoothing Techniques." In Advances in Intelligent Systems and Computing, 229-39. https://doi.org/10.1007/978-981-13-1882-5_21.

Dunstan, Piers K., Bradley R. Moore, Johann D. Bell, Neil J. Holbrook, Eric C.J. Oliver, James Risbey, Scott D. Foster, Quentin Hanich, Alistair J. Hobday, and Nathan J. Bennett. 2018. "How Can Climate Predictions Improve Sustainability of Coastal Fisheries in Pacific Small-Island Developing States?" Marine Policy 88 (February): 295-302. https://doi.org/10.1016/j.marpol.2017.09.033.

Golding, Nicola, Chris Hewitt, Peiqun Zhang, Min Liu, Jun Zhang, and Philip Bett. 2019. "CoDevelopment of a Seasonal Rainfall Forecast Service: Supporting Flood Risk Management for the Yangtze River Basin." Climate Risk Management 23: 43-49. https://doi.org/10.1016/j.crm.2019.01.002.

Hartomo, Kristoko Dwi, Subanar, and Edi Winarko. 2015. "Winters Exponential Smoothing and ZScore, Algorithms for Prediction of Rainfall." Journal of Theoretical and Applied Information Technology 73 (1).

Hyndman, Rob J., Anne B. Koehler, J. Keith Ord, and Ralph Snyder. 2010. "Forecasting with Exponential Smoothing: The State Space Approach." International Journal of Forecasting 26 (1): 204-5. https://doi.org/10.1016/j.ijforecast.2009.09.005.

Metcalfe, Andrew V., and Paul S.P. Cowpertwait. 2009. Introductory Time Series with R. Introductory Time Series with $R$. New York, NY: Springer New York. https://doi.org/10.1007/978-0-387-88698-5.

Noviandi, and Ahmad Ilham. 2020. "Optimization Fuzzy Inference System Based Particle Swarm Optimization for Onset Prediction of the Rainy Season." Kinetik: Game Technology, Information System, Computer Network, Computing, Electronics, and Control 5 (1): 61-70. https://doi.org/https://doi.org/10.22219/kinetik.v5i1 .985 .

Pascawati, Nur Alvira, Tri Baskoro Tunggul Satoto, Tri Wibawa, Roger Frutos, and Sylvie Maguin. 2019. "Dampak Potensial Perubahan Iklim Terhadap Dinamika Penularan Penyakit DBD Di Kota Mataram.” BALABA: Jurnal Litbang Pengendalian Penyakit Bersumber Binatang Banjarnegara 15
(49-60). https://doi.org/10.22435/blb.v15i1.1510. Wichitarapongsakun, Patana, Charoon Sarin, Pantip Klomjek, and Sombat Chuenchooklin. 2016. "Rainfall Prediction and Meteorological Drought Analysis in the Sakae Krang River Basin of Thailand." Agriculture and Natural Resources 50 (6): 490-98. https://doi.org/10.1016/j.anres.2016.05.003.

Zhu, Mengxun, Hans J. De Boeck, Hang Xu, Zuosinan Chen, Jiang Lv, and Zhiqiang Zhang. 2020. "Seasonal Variations in the Response of Soil Respiration to Rainfall Events in a Riparian Poplar Plantation." Science of The Total Environment 747 (December): 141222 . https://doi.org/10.1016/j.scitotenv.2020.141222. 